\title{
Resourcing for a resilient post-disaster reconstruction environment
}

\author{
Yan Chang ${ }^{1}$, Suzanne Wilkinson ${ }^{2}$, Erica Seville ${ }^{3}$, and Regan Potangoroa ${ }^{4}$
}

\section{Affiliation of Authors and Full Correspondence Address}

${ }^{1}$ Ph.D. student, Department of Civil and Environmental Engineering, The University of Auckland, New Zealand

Correspondence Address: Department of Civil and Environmental Engineering, The University of Auckland, Private Bag 92019, Auckland Mail Centre, Auckland 1142, New Zealand

E-mail: ycha233@aucklanduni.ac.nz; alicechang918@hotmail.com

2 Associate Professor, Department of Civil and Environmental Engineering, The University of Auckland, New Zealand

Correspondence Address: Department of Civil and Environmental Engineering, The University of Auckland, Private Bag 92019, Auckland 1061, New Zealand

E-mail: s.wilkinson@auckland.ac.nz

${ }^{3}$ Associate Professor, Department of Civil Engineering, University of Canterbury, New Zealand Correspondence Address: Department of Civil Engineering, University of Canterbury, Private Bag 4800, Christchurch 8140, New Zealand

E-mail: erica.seville@canterbury.ac.nz

${ }^{4}$ Associate Professor, School of Architecture (ScALA), UNITEC, New Zealand

Correspondence Address: School of Architecture (ScALA), Building 1, Carrington Road Mt Albert, UNITEC, Private Bag 92025, Auckland, New Zealand

E-mail: rpotangaroa@unitec.ac.nz 


\section{Author Correspondence}

Yan Chang, Ph.D. student, Department of Civil and Environmental Engineering, The University of Auckland, Private Bag 92019, Auckland Mail Centre, Auckland 1142, New Zealand. E-mail: ycha233@aucklanduni.ac.nz; alicechang918@hotmail.com

\section{Acknowledgments}

As part of 'Resilient Organisations' research program (2004-2010) www.resorgs.org.nz, the research was supported by the Foundation of Research Science and Technology (FRST). The authors wish to thank CARE International in Banda Aceh, Indonesia, Construction Bureau of People's Government of Mianzhu, Sichuan Province, P.R. China and Faculty of Architecture and Environmental Engineering of Sichuan University, Chengdu, China for their assistance in data collection for this study. 


\title{
Resourcing for a resilient post-disaster reconstruction environment
}

\begin{abstract}
Purpose - The purpose of this study is to understand the resourcing issues that concern the provision of resources required for reconstruction projects after a disaster and to enable them to be integrated into a holistic planning process.

Design/methodology/approach - Triangulation methodology was adopted in this study including both quantitative and qualitative methods. The quantitative approach, namely statistic analysis with the aid of questionnaires and SPSS was employed to identify the key factors affecting resource availability in post-disaster reconstruction situations. The qualitative semistructured interviews and desk reviews of government and media documents were conducted to further interpret outcomes in the questionnaire session.
\end{abstract}

Findings - Based on empirical research, the major finding of the paper is that in order to arrive at a resilient and sustainable built environment after a disaster, resourcing efforts should be made around four components: (1) resourcing facilitator: legislation and policy, (2) resourcing implementer: construction industry, (3) resourcing platform: construction market, and (4) resourcing access: transportation system.

Research limitations/implications -Based largely on China's Wenchuan earthquake (2008) rebuilding experience, the study proposes a holistic view of where resourcing bottlenecks are likely to exist during post-disaster reconstruction and where efforts are needed to align resources more closely to reconstruction requirements. The future research challenge resides in, under the topic of the post-disaster resourcing, how to generalize the research results yielded from China's case and draw out similarities and differences among different disaster relief and recovery systems.

Practical implications - The data collection was conducted on a basis of field investigation. The empirical perspectives and insights were captured of those who are involved in rebuilding after the Indian Ocean tsunami and in post-Wenchuan earthquake reconstruction in China. Thus, the 
findings of this paper have practical implications for post-disaster reconstruction. Specific approaches are suggested with identified components incorporated to facilitate resourcing operations. The research helps draw attention to these items and raise understanding of the key role of pre-event resource planning and preparedness to enhance built environment resilience.

Originality/value - The original part of this paper is in raising the importance of resourcing for achieving a resilient post-disaster built environment, and in presenting a thorough overhaul of the resourcing components. The paper also (1) offers a vision of comprehensive planning and preparedness to facilitate resourcing operations in post-disaster reconstruction; (2) pinpoints possible constraints inherent in post-disaster resourcing environment; (3) provides a directionsetting framework to achieve the vision with built environment resilience considerations incorporated.

Keywords Post-disaster reconstruction, resourcing, resilience, planning and preparedness

Paper type Research paper

\section{Introduction}

Post-disaster reconstruction is one of the most challenging tasks confronting decision makers and recovery practitioners in disaster-affected areas. After the 2004 Indian Ocean tsunami, the principle of 'Build Back Better' was taken to heart by the post-tsunami reconstruction efforts which were predominantly geared towards longer term, sustainable development. The emphasis was on assessing pre-existing problems and dealing with deeper development issues so that the actions carried out improve the lives of people affected and of future generations (ERRA, 2006; United Nations Thailand, 2005; Clinton, 2006).

However, 'Resilient Organizations' (2007) and other researchers such as Paton and Johnston (2001) and Manyena (2006) advocate a focus on a community coping capacity to thrive rather than just survive when a disaster strikes. Recent disaster experiences such as Hurricane Katrina and Hurricane Rita have highlighted visible improvements in the way the recovery system organized itself around enhancing community resilience (Berke and Campanella, 2006; Litman, 2006). Increased attention is paid to what affected communities can do for themselves and how 
best to strengthen them (IFRC2004). Resilience has increasingly become a watchword to refine and reshape post-disaster reconstruction.

Past events have proven that obtaining adequate funding, and high quality physical and technical assistance is a primary issue for achieving a resilient post-disaster built environment. The repeated failure of many projects can be attributed to the shortage and unavailability of resources required for reconstruction. A lack of building materials including sand, stone, cement, timber and brick for housing reconstruction in Aceh and Nias was a major bottleneck in post-Indian Ocean tsunami recovery process (ADB, 2007; Nazara and Resosudarmo, 2007; Zuo and Wilkinson, 2008). The shortage of aggregate, human resources and heavy equipment has been identified as one of the potential constraints to the recovery process in New Zealand if a largescale disaster strikes (Brunsdon and Smith, 2004; Singh, 2007). Other resourcing-related problems such as ineffective resourcing approaches, poor resource management, and speculative behaviors of material procurement, along with environmental concerns induced by intensified logging and mining activities after a disaster have reduced the effectiveness of recovery in disaster-impacted countries (UNDP2005; IFRC2006).

In addition, a number of experiences have confirmed positive results when resource bottlenecks are dealt with by new post-disaster policies. During Tangshan earthquake (1976) recovery, for instance, much of the period was devoted to physical reconstruction whereby "A master plan was formulated, heavy equipment was purchased and industrial plants were established to produce reconstruction materials" (Mitchell, 2004, pp. 52). Many studies concerning resource deployment and allocation, however, are mainly targeted at emergency response to meet shortterm humanitarian relief needs after a disaster (e.g. (Perry and Lindell, 2003; Thompson et al., 2006; Troy et al., 2008)), overlooking the resource planning and preparedness for long-term post-disaster reconstruction (Alexander, 2004; Orabi et al., 2009). A number of scholars such as Ye \& Okada (2002) and Sullivan (2003) have recognized that desirable post-disaster reconstruction could only be made possible by systematic recovery planning with a focus on making the resources required available for long-term reconstruction. Comprehensive pre-event preparedness is thus an integral element in the ultimate effectiveness of post-disaster recovery efforts. 
In spite of the above propositions, the issue of resourcing for post-disaster reconstruction has not been adequately debated in academic and practical forums. Resourcing, as defined in this paper, calls for an integrated connection with all stakeholders and a cohesive resourcing approach that embraces those actors into an adaptive process for resource provision. This paper deals with four themes pertinent to resourcing for post-disaster reconstruction: legislation and policy, construction industry, construction market, and transportation system. An empirical analysis, based largely on China's Wenchuan earthquake (2008) rebuilding experience, of the resourcing practice and outcomes during post-quake reconstruction is presented. Specific approaches are suggested for enhancing the overall resourcing capability for post-disaster reconstruction.

\section{Background}

In comparison to pre-event project construction, the post-disaster reconstruction environment is more dynamic, complex, and unpredictable (Berke et al., 1993; Alexander, 2004; Birkland, 2006). Post-disaster reconstruction projects are susceptible to resourcing bottlenecks, such as lack of resources and alternatives, limited sources of resources, and difficulty in accessing the resources that are required for reconstruction. These impediments to resource acquisition can be attributed to the impact of the disaster and vary according to the urgency and scale of reconstruction.

With the large-scale and intensive reconstruction unfolding in August 2008, China was, however, not immune to the various resourcing problems discussed above. An explicit lack of resources required for housing reconstruction combined with implicit resourcing capacity bottlenecks significantly limited the degree to which successful recovery could occur. Such a difficulty made it mandatory for reconstruction planners and project managers to build the capability to continuously adapt themselves to the evolving conditions to cope with emerging resourcing problems.

The Wenchuan earthquake serves as an exemplar for the disproportionate volume between resource demand and supply during widespread and intensive rebuilding work (See Table 1). The supply shortfalls of building materials in Table 1 indicate that the reconstruction demand was sufficient to pose difficulty to reconstruction practitioners in procurement of these materials. 
Labour scarcity was another problem leading to precipitous wage increases undermining the functionality of local construction market.

Table 1 Supply breakdowns of cement, brick and steel in earthquake-stricken areas

\begin{tabular}{l|c|c|c}
\hline Construction materials & $2008-2009$ & $2009-2010$ & $2010-2011$ \\
\hline Cement (million tons) & 53 & 39 & 31 \\
Brick (billion pieces) & 35.5 & 17.8 & 3 \\
Steel (million tons) & $3-3.6$ & $3-3.6$ & $3-3.6$ \\
\hline
\end{tabular}

Source: http://www.sc.gov.cn

Furthermore, post-disaster construction techniques and standards adopted as mandatory by central government often exclude the use of traditional technologies and materials (Schilderman, 2004). During the post-Indian ocean tsunami reconstruction, the government in impacted areas encouraged the use of environment-friendly, low cost and seismically resistant materials by providing relevant preferential policies. Nevertheless, new recommendations on construction methods and earthquake resistant materials were not popular and accepted by local traditions and customs. A lack of understanding of new construction materials and techniques hindered their wide use and application in the affected areas (Steinberg, 2007; Roseberry, 2008).

There was an imperative to complete rebuilding of permanent residences before winter for people affected by Great Pakistan Earthquake in North Pakistan (2005) and those impacted by Wenchuan Earthquake in China (2008). Given the urgency of reconstruction in events of this nature, if not enough time is allocated to reconstruction planning and scheduling, or normal planning procedures and construction legislation are bypassed, the project is more likely to suffer resourcing bottlenecks (Resilient Organisations, 2006), leading to cost escalation (Davidson et al., 2008; Jayasuriya and McCawley, 2008), poor reconstruction quality (Zuo et al.2006), and project delays (Steinberg, 2007).

Singh (2007) concluded that lead times associated with acquiring materials in post-disaster situations can be detrimental to the availability of required resources, especially in a construction industry which relies heavily on "just-in-time" delivery. Furthermore, the fact that most reconstruction projects are likely to be fast tracked essentially means that lead times and delays 
will be even more critical to resourcing practice after a disaster (Rowland, 1995; Masurier et al., 2008). Some reconstruction failure examples can be traced back to low resource coverage and long lead time in the resource acquisition process (Steinberg, 2007; Zuo and Wilkinson, 2008). In China's Wenchuan earthquake reconstruction, however, the prolonged lead-time of rebuilding projects was mainly caused by transport disruption and persistent rain during the reconstruction period.

In an attempt to address resourcing problems after a disaster, many traditional methods have been employed such as regulating the market to stem post-disaster inflation (Jayasuriya and McCawley, 2008), importing resources from overseas (Zuo and Wilkinson, 2008), and reallocating funds from existing projects to meet recovery needs (Freeman, 2004). These approaches and last-minute improvisations at the ad hoc operational level seem to be unable to perform well to alleviate resource shortages. The key aspects of a successful resourcing approach including input requirements, market linkage, infrastructure settings and key stakeholders interactions are not yet being addressed. In addition, the absence of pre-event resource planning and preparedness, the inadequacy of efficient and flexible institutional arrangements, and the paucity of pro-active engagement of the construction industry into disaster management are still visible contributors to undermining resourcing performance in a post-disaster environment.

Resourcing broadly encompasses a wide range of activities that have a bearing on resource management for post-disaster reconstruction projects, embracing pre-event resource planning and preparedness, resource procurement, resource delivery, and development of resource alternatives. Despite the inherent link between post-disaster resourcing and reconstruction performance, little research has been undertaken to examine this connection. The need for an indepth investigation on the resourcing methods and related intrinsic problems in post-disaster rebuilding environments is, therefore, essential for a better resource-ensured reconstruction. To fulfil this need, a longitudinal case study in China's Sichuan Province has been developed by authors from six weeks after the earthquake until to date, with a focus on understanding existing practices and identifying the challenges which confront the decision makers and practitioners in such an environment. For the purpose of this paper, four principal components of resourcing post disaster: (1) resourcing facilitator: legislation and policy; (2) resourcing implementer: construction industry; (3) resourcing platform: construction market; and (4) resourcing access: 
transportation system were identified and discussed as having a significant impact on a successful resourcing post disaster. Management of these four components could reduce the frustrations in the post-disaster resourcing environment.

\section{Research Methodology}

The methodology adopted in this study is commonly known as triangulation (Todd, 1979) which mixes qualitative and quantitative methods in research. The quantitative approach, namely statistic analysis with the aid of questionnaires and SPSS was employed to identify the key factors affecting resource availability in post-disaster reconstruction situations. The qualitative semi-structured interviews and desk reviews of government and media documents were conducted to clarify and reinforce conclusions yielded in the questionnaire session.

Apart from the factors identified from literature, a pilot study was undertaken in a manner of independent interviews with three experienced construction coordinators from NGOs involved in post-tsunami housing reconstruction program in Indonesia to supplement and rectify the questionnaire. The final designed questionnaire contains 37 factors which are regarded by the literature and pilot study to have a potential influence on resource availability for post-disaster reconstruction (See Appendix Table 3).

The questionnaire survey was conducted with contractors that have been operating in postWenchuan earthquake reconstruction work in China. The sampling frame contained 218 building contractors registered with Construction Bureau of People's Government of Mianzhu. In the questionnaire, the respondents were asked to rank the importance of each factor in achieving resourcing outcomes of post-disaster reconstruction projects on a five-point Likert scale from 1 to 5, where 1 symbolizes 'not important at all' and 5 represents 'very important'. The questionnaire also requested the informants to add any other potential factors and rate them accordingly. The questionnaires were sent by post, email or personal delivery by the researchers in field trips to 90 randomly selected rebuilding contractors and 29 valid responses returned with the response rate of $32.2 \%$. 
By using SPSS software package, the significance of 37 factors identified in the research were ranked in Appendix Table 3. The ranking hierarchy of 10 most significant factors is tabulated in Table 2. The top ten determinants were legislation and policy, project schedule, competency of resourcing manager, qualification of contractor, project resourcing plan, quantity of materials required, resource procurement lead time, general economic environment, transportation cost and transportation method.

Table 2 Ranking hierarchy of factors affecting resource availability in post-disaster reconstruction

\begin{tabular}{clc}
\hline Rank & $\begin{array}{l}\text { Factors affecting resource availability } \\
\text { in post-disaster reconstruction }\end{array}$ & Mean \\
& & \\
\hline 1 & Legislation and policy & 4.83 \\
2 & Project schedule & 4.66 \\
3 & Competency of resourcing manager & 4.59 \\
4 & Qualification of contractor & 4.59 \\
5 & Project resourcing plan & 4.59 \\
6 & Quantity of resources required & 4.59 \\
7 & Resource procurement lead time & 4.59 \\
8 & General economic environment & 4.55 \\
9 & Transportation cost & 4.55 \\
10 & Transportation method & 4.48 \\
\hline
\end{tabular}

According to the actual content and internal features of the identified variables in Table 2, content analysis research tool which contains a conceptual analysis and a relational analysis (Krippendorff, 1980) was applied to categorize these 10 factors into four principal groups with the following headings: legislation and policy related factors, construction industry related factors, construction market related factors, and logistics-related factors. Based on which, the four components of post-disaster resourcing were proposed: (1) resourcing facilitator: legislation and policy; (2) resourcing implementer: construction industry; (3) resourcing platform: construction market; and (4) resourcing access: transportation system. Further interviews were conducted in earthquake-impacted areas with 16 reconstruction contractors (coded C1-C16) who contributed in the questionnaire phase. Within the interviews, qualitative data was captured around the following three issues: 
- possible interpretations of the effects of critical factors on resourcing outcomes.

- specific resourcing bottlenecks and instruments in the reconstruction process; and

- resourcing initiatives that have been taken for post-Wenchuan earthquake reconstruction in China;

The interview sessions were voice recorded, transcribed and coded. Quotes and comments from the interviews were confirmed and approved by the interviewees. A couple of these citations are presented in the paper as representative in regard to the specific subjects to help illustrate the points raised. The rest of the data from interviews are treated as part of the overview of China's resourcing practice after the Wenchuan earthquake in the remainder of the paper which covers the four proposed themes. Consideration was given to the perceived implications of each component of resourcing in the contemporary post-disaster context with an in-depth analysis, based on which future directions were suggested for improvement of resourcing in arriving at a resilient post-disaster reconstruction environment.

\section{Resourcing facilitator: Legislation and policy}

\section{Implications of legislation and policy for resourcing practice post disaster}

Legislation and policy packages have been regarded by a number of researchers as an overarching imperative to allow effective coordination and delivery of reconstruction work (Godschalk, 1999; McEntire et al.2002; Birkland, 2006; Masurier et al., 2008). However, the reconstruction facts in Indonesia and Sri Lanka after the Indian Ocean tsunami (2004), and in New Orleans after Hurricane Katrina (2005) revealed that pre-existing legislation and policy seemed to be unable to cope with post-disaster situations (Zuo et al., 2008), especially after a large-scale disaster (Masurier et al.2006); inappropriate legislative and governmental system could substantially limit the recovery progress (Burby, 2006; Nazara and Resosudarmo, 2007; Lyons, 2009) and hinder reconstruction resource procurement and utilization (Hanaoka and Qadir, 2005).

As for the Wenchuan earthquake, for instance, the majority of provisions in the pre-existing disaster-related laws such as the Emergency Response Law of the People's Republic of China (2007) and the Law of the People's Republic of China on Protecting against and Mitigating 
Earthquake Disasters (1998) only provided guidelines for disaster response as opposed to recovery and reconstruction. Furthermore, according to the interviewees, the lack of specific legislative and regulatory schemes concerning insurance for large-scale disasters and natural resource conservation and utilization in reconstruction after a disaster, to a great extent, handicapped the delivery of projects in the earthquake affected areas.

Two laws issued after the Wenchuan catastrophe, however, played a significant role in supporting recovery programs by channelling and mobilizing resources nationwide. The Regulations on Post-Wenchuan Earthquake Restoration and Reconstruction (2008) set guidelines for the reconstruction and provided important legal grounds for various departments and government agencies to assist with post-quake recovery and reconstruction. As an adjunct policy, One-on-one Assistance Program for Post-Wenchuan Earthquake Restoration and Reconstruction (2008) was instrumental in providing fiscal, physical and human-power resource assistance and provision for the earthquake-impacted areas. According to the program, the earthquake-stricken areas were divided and twinned with relatively developed localities across China. Sister localities were tasked over the next three years with funding $1 \%$ of their GDP, provision of human resources and temporary housing units, and in-kind support from planning institutions and other departments.

\section{Future directions to improve legal system}

There is a growing need to assist reconstruction practitioners for a better level of resourcing through balanced strategies combining both mandated and incentive approaches. The development of a legal framework at the national level to facilitate pre-event resource planning and preparedness along with post-disaster resourcing operations is required. Efforts need to be made to put in place comprehensive and compatible legislation and policy packages that cater for post-disaster reconstruction with long-term sustainability considerations incorporated.

Current legislation needs careful revamping to serve as a facilitator to support resourcing and to reduce potential risks and vulnerabilities in disaster affected or prone areas. Endeavours should be made to review the existing legislation and to develop a specific legislative portfolio compatible with resourcing needs for long-term recovery and reconstruction post disaster. For instance, by upgrading the law for logging and reforestation to make local wood resources 
accessible to the people affected without detriment to natural environment; and by changing buildings codes to promote the acceptance and application of advanced and cost-effective materials for reconstruction projects.

Legislation should be enforced in combination with flexible policies to oversee and provide guidelines for various resourcing issues, such as retail price control for building materials, natural resource exploitation, financial subsidizing for the affected population, quality supervision of construction materials and equipment, and applying new construction standards and materials to rebuilding projects.

Policy development to facilitate resource availability for post-disaster reconstruction requires knowledge regarding the possible vulnerable resources, the breakdowns between supply and demand, and likely alternative resources and transportation methods. To enhance the ability to deal with disaster situations, decision makers at different levels require consistent training and learning to understand and to cope in the post-disaster environment.

In reconstruction planning and prioritization, appropriate decisions about the pace and sequencing of construction activities are needed. Streamlined decision making procedures for resource procurement should be put in place early. There is a need for local authorities to develop interdisciplinary, inter-organizational coordination mechanisms for integrating different disciplines into local resource planning and preparedness programs. It is also advisable to develop a registration system of trained and skilled personnel and a comprehensive resource database in either governmental construction department or local industry association.

\section{Resourcing implementer: construction industry}

\section{Significance of construction industry in resourcing implementation post disaster}

The construction industry is not only a critical component of the nation's economy, but also a fundamental contributor in disaster management and mitigation (Spence and Kelman, 2004; Pheng et al.2006; Zuo et al.2006). Past practice demonstrated a challenge for construction project management in relation to the resource delivery process which requires the commitment of the resourcing professionals and large-scale construction organizations in post-disaster 
reconstruction. Some interviewees $\mathrm{C} 2-\mathrm{C} 6, \mathrm{C} 8$ and $\mathrm{C} 12$ highlighted the main pronounced difference of project management in post-disaster rebuilding, as C2 stated:

'In comparison with pre-event construction, project managers working on post-disaster projects need to abide by local reality of limited resources and constraints, of lack of access to resources, and of the chaos originated by the disastrous event'. (C2)

Although much attention was given to the competency of project managers in construction projects (Edum-Fotwe and McCaffer, 2000; Pheng and Chuan, 2006), responsibility for resourcing mainly falls to the functional manager in charge of resource procurement. Singh and Wilkinson and Zuo et al. (2008) propose a more proactive role for resourcing managers in resource procurement under post-disaster reconstruction circumstances where the broader social aspects are required such as environmentally responsible behaviour (Chang et al.2006), and maintaining the intimate relationships with stakeholders (Edum-Fotwe and McCaffer, 2000).

The credentials of the contractor is regarded as a key element to resource procurement during an emergency (Lyons, 2009). Large and well-established businesses are more likely to recover faster and be able to engage in reconstruction (Athukorala and Resosudarmo, 2005), and procure resources needed in a disaster context due to their well-established long-term relationships with subcontractors and suppliers (Zuo et al., 2006). These linkages determine the successful acquisition of resources in the hierarchy of post-disaster reconstruction (Masurier et al., 2006). Larger contractors are likely to have more competent resourcing professionals. The negotiation skills, effective communication and scheduling with the suppliers, and qualifications of those engaged in resource procurement constitute an essential part of the capability of the organization to better handle resourcing tasks in post-disaster situations.

Recent disasters have highlighted the role of the construction industry in the disaster-stricken areas and their inadequate engagement in the mitigation of such events (Pribadi et al., 2003; Gharaati, 2006; Pheng et al., 2006). For example, in Banda Aceh, Indonesia, the quality of posttsunami reconstruction projects was largely impaired by the low quality of local construction practitioners. The use of building materials of poor quality and low-skilled labour further added risks to future disasters, which resulted in costly financial waste and a dysfunctional recovery system in the tsunami impacted region. 
Likewise, the construction industry in China has not been sufficiently involved in disaster planning and management. In spite of resourcing facilitation efforts made by the Chinese government, the local contractors and reconstruction organizations in the earthquake-affected areas appeared to be less proactive in reconstruction resource procurement. Except for a few large national construction companies which had resourcing contingency plans integrated into the overall project plan, there were no set schemes and strategies regarding post-disaster reconstruction, and the awareness of engagement into disaster management was poor. As some of the interviewees stated:

'We just do what we normally need to do in the construction process according to the requirements of regulatory agencies and house owners' (C3); 'We really didn't realise we are contributing to reduce vulnerability of potential disaster risks' (C7, $\mathrm{C} 10$, and $\mathrm{C} 14)$; and 'Even we knew our significant role in future disaster prevention, disaster management and construction still appear to be separate subjects' (C12 and $\mathrm{C} 15)$.

This situation bears resemblance to that of other countries such as Indonesia (Pribadi et al., 2003), Iran (Gharaati, 2006), Sri Lanka (Pheng et al., 2006) and UK (Bosher et al., 2007). The segmentation between disaster management and construction sectors is manifested in many aspects in these countries, such as in education, planning, operations and daily activities. This, to a great extent, hinders the inclusion of professions from the built environment into hazard mitigation on a sustainable agenda.

\section{Future directions to enhancing post-disaster resourcing capability}

Initiatives from the construction industry should focus on policy amendments and capacity building innovations through cooperation and partnerships with government agencies and other related stakeholders such as resource suppliers, market regulators and construction clients. In addition, the salient contributions of large-scale contractors and competent resourcing professionals in resource acquisition within a disaster context should be recognized.

There is a need within the construction industry to design programs to heighten the awareness of industry players to engage in disaster management, planning and mitigation. Involving construction-related stakeholders in local emergency management departments and other disaster mitigation programs could improve the overall awareness in the industry. Partnerships with 
suppliers, institutions, authorities to enhance building codes, standards, new materials and construction technologies after a disaster could also encourage construction practitioners to get involved in the future development of mitigation measures in hazard and risk areas.

There is a requirement for resource availability to be integrated into a project resource management framework to ensure a strategic vision in the project resourcing process. Construction project resourcing plans should involve proactive and preventive schemes for potential resourcing bottlenecks in a post-disaster environment. This calls for a wide consultation and connection with all relevant stakeholders in the resourcing process to assist recovery planning, identify constraints, and help accelerate the pace and quality of resource provision and delivery. When in possession of up-to-date information, the project tasks in which resource availability acts as a constraint can be identified, and rescheduled to a time where the resource needs are satisfied.

As the main operators in the physical reconstruction and rehabilitation after a disaster, the construction sector in China needs to take steps to improve resourcing capability rather than rely on preferential policies and administrative interventions from governmental authorities. Largescale industry players should take a lead responsibility to enhance the overall resourcing capability in the industry by providing information and knowledge sharing programs for small and medium businesses. A more proactive approach to supporting and training for resourcing professionals is needed. Capability of resourcing professionals could be strengthened through provision of training on cost estimates, negotiation skills, formulation of strategies, and technical assistance and consultancy services for preparation of resourcing plans and purchasing documents.

Furthermore, improvements in regional stockpiling of supplies and equipment, pre-event resource inventory strategy for lifeline infrastructure reconstruction, and development of alternative procurement methods might also be favourable options for coping with resource shortages in post-disaster situations.

\section{Resourcing platform: construction market}

\section{Critical market links with resourcing stakeholders post disaster}


Although the roles of the construction industry in disaster mitigation and prevention have been identified (Pheng et al., 2006; Bosher et al., 2007; Lakshmi and Bau, 2007), the essential function of the construction market in post-disaster reconstruction has been largely neglected in the discourse on disaster management (Athukorala and Resosudarmo, 2005). The construction market acts as the source of reconstruction resources, but can also generate inflation, profiteering and 'Dutch disease' after a disaster (Jayasuriya and McCawley, 2008). In response to these issues, governmental authorities tend to resort to 'hard intervention' solutions through price restrictions and transaction regulations which, however, might cause resources to be allocated inefficiently and could serve to delay disaster relief (McGee, 2008). This is also substantiated by reconstruction examples in the aftermath of Wenchuan earthquake (2008). Apart from legal support for resource allocation nationwide, Chinese authorities enforced tight price control and market regulatory interventions to deal with inflation caused by resource shortage after the catastrophe. These interventions encompass price restructuring in brick, cement, aggregate and other resources, designating production supply, and assigning inspectors to businesses to monitor retail price. Although these initiatives, to some degree, eased the tension of material supply in earthquake-affected areas, they also imposed a major disincentive to other suppliers to actively get engaged in post-disaster resourcing operations. The official order for suppliers to provide resources to particular impacted areas led to imbalanced and instable material inputs needed in other affected areas, and further induced secondary interest conflicts in the construction market.

Meanwhile, the building of 75 cement production lines, 760 brick factories and 2 large-scale high-performance steel manufactories was sanctioned by local government to meet the intensive and massive reconstruction needs at the early stage (SPPG2008). However, with supply gradually outpacing demand at the late stages of reconstruction, excess productivity is likely to have a negative effect on local economy and market in the long run.

\section{Future directions to building a resilient construction market}

The discussion above indicates that reliance on mandated resolutions and increasing production methods is unable to solve the root problems of resource availability in post-disaster environment; rather it would possibly bring about new vulnerabilities affecting the sustainable development of local construction market. The trade-off between levels of macro control and market self-regulation posed a challenge for Chinese policy makers to settle different and 
conflicting interests of stakeholders without detriment to the disaster-affected areas. To deal with disaster situations, the construction market should serve as a platform where resourcing activities such as rebuilding production facilities, developing resource alternatives, and restructuring local productivity could be promoted. By connecting these schemes with local government policies and programs, the construction market could become more sustainable.

The commercial ties between stakeholders in the construction market are fragile and temporary due to the interest-oriented nature of transactions. In order to establish solid partnerships and links, there is a need for the authorities concerned to design a variety of training and learning programs in the construction market to get stakeholders involved. Substantial involvement of supply chain actors and decision-making authorities is critical to these initiatives. To make the market more resilient, communication between businesses and local authorities may offer a significant opportunity for sensible planning, layout and development of local construction market. Academic organizations and the construction sector need to provide appropriate technical assistance and advice to strengthen this partnership.

Local supply capacity of resources for disaster response and recovery constitutes a critical part of resilience and sustainability of the economy and market in disaster affected areas. To seek a more systematic and robust supply system after a disaster, attention should be placed on planning to identify relevant supply problems and concerns in order to restore the balance between supply and demand in the medium or long term. This approach calls for a process that ensures broad involvement and participation by all the stakeholders in the construction market in decision making in order to develop ideas and reach agreement on the resource supply strategies in the market. Damaged facilities need to be rebuilt with the benefit of more efficient and environmentfriendly production technology. Further supply capacity expansions could come with the entry of a reasonable number of new players.

Apart from expanding the provision capacity of local supplies and services in the construction market, resource availability can be improved by the introduction of a variety of alternatives and resourcing methods. Implementing agencies in the local construction market should encourage new investment in production, development of alternatives on a basis of maximum utilization of local resources. Introducing incremental alternatives of resources nationally and internationally into the disaster-affected areas is an optimal supplementary if the corresponding operational 
mechanism is established for channelling physical, technical and financial inputs from overseas markets and agencies in a quick and effective manner.

\section{Resourcing access: transportation system}

\section{Life-line function of transportation for resourcing post disaster}

The transportation systems such as roads, airports, railways provide essential access to available resources needed for a country's rapid and successful recovery. Some studies looking into postdisaster logistics have shown that the high cost of resource transportation (Limoncu and Celebioglu, 2006) and lack of delivery alternatives (Singh, 2007) were a major concern in postdisaster reconstruction. According to Asian Development Bank (2007), after the Indian Ocean tsunami, the impacted Aceh experienced a shortage of cement, which, coupled with price speculation, drove up cement prices in Aceh by 63\%. A significant portion of this price gap is attributed to high transportation costs as a result of the limited port and shipping capacity along with lengthy transportation times.

The devastating Wenchuan earthquake also highlighted the vulnerability of the transportation system in China. Road and railway systems in the earthquake-affected areas were mainly damaged and cut off by a large number of secondary hazards such as landslides, landslips, mudrock flow and 'quake lakes'. Reopening access was a slow process due to the particular mountainous topology, constant aftershocks and persistent rain. Lack of access and consistency in delivery, together with volatile price fluctuation of fuel in Chinese market greatly inhibited the recovery process.

All modes of transport were utilized, including human-power and animal carrying methods to deliver building materials to construction sites in post-Wenchuan earthquake reconstruction. The Transport Ministry of China approved four river-land joint routes for large cargo delivery. The Transport Network Planning Program was devised and launched after the earthquake incorporating the concept of the Lifeline Highway Network. It required at least more than two highly earthquake-resistant highways to reach other jurisdictions in each quake-affected town and the total length of the network was 4900 kilometers. Three railway construction programs, such as Dujiangyan-Chengdu express line, were also put on agenda (State Planning Group2008).

\section{(c) Emerald Group Publishing Limited}

This is a pre-print of a paper and is subject to change before publication. This pre-print is made available with the understanding that it will not be reproduced or stored in a retrieval system without the permission of Emerald Group Publishing Limited. 
Transport capacity-extending strategies for reconstruction in China to a great extent eased the tension of resource transport, but according to the interviews, led to a conflict between normal delivery activities and reconstruction needs, adding difficulty in overall coordination and deployment of resources nationwide. In comparison with the pre-event situation, the increasing cost of new transport alternatives also had an adverse effect on efficient and timely resource delivery to rebuilding projects.

\section{Future directions to developing a robust transportation network}

In achieving a robust transportation network after a disaster, the emphasis needs to be placed on how to develop and strengthen relevant institutions and mechanisms that could help expand lifeline networks. The development of transportation networks along with reconstruction and rehabilitation of the damaged infrastructure should be implemented in a technically sound, costeffective, and economically and socially compatible manner to ensure improved quality, access and service delivery.

Quick restoration of transportation links should have top priority in the immediate aftermath of a disaster so that relief resources can be delivered to the affected populations. However, the majority of the repair work is temporary and the access remains prone to frequent disruptions induced by aftershocks and secondary hazards. Upgraded specifications should thus be considered in transport reconstruction planning and implementation to reduce the vulnerability of restored accesses to a wide variety of future hazards.

To improve resource accessibility and ensure logistical affordability, an expansion of transportation system with alternative networks is of strategic significance. The transport capacity extending strategies should be integrated into the pre-disaster mitigation program and should be targeted at transport alternatives to enhance the resistance and resilience of the overall transportation system to future disasters. In addition, planning for transport reconstruction should be in line with industrialization and urbanization in the earthquake-impacted areas taking account of natural environmental conditions and capacity.

The transportation networks should be planned and developed along with other lifeline utilities and public facilities, such as communication, electricity and water. The corresponding

\footnotetext{
(C) Emerald Group Publishing Limited

This is a pre-print of a paper and is subject to change before publication. This pre-print is made available with the understanding that it will not be reproduced or stored in a retrieval system without the permission of Emerald Group Publishing Limited.
} 
institutions and a specific fully-empowered agency need to be established to make the management and coordination of different lifelines smooth and effective.

\section{A synthesis vision for decision making}

The retrospective review of resourcing operations for housing reconstruction after China's Wenchuan earthquake highlights the significance of the four identified areas with regard to resource availability in a post-disaster environment. However, a vision which synthesizes these four areas is required for better resourcing outcomes. It would require concerted commitment from stakeholders and a multi-sector approach. Understanding and communication among stakeholders can make it possible to develop a collaborative planning process. To achieve this, development of high quality, systematic data collection methods, information management systems, and communication and coordination mechanisms are needed. Regular communications between these stakeholders - for example, by means of meetings, workshops and seminars organized by the government can provide a platform. In this regard, government needs to take a lead role of coordination and facilitation to support fully inclusive planning processes both before and after the event to ensure resource availability for post-disaster reconstruction.

Albeit each country has primary responsibility for its own post-disaster reconstruction and recovery, an enabling international environment is vital to stimulate and contribute to developing the knowledge, capabilities and motivation needed to build disaster resilient nations and communities. Developing specific mechanisms to engage the introduction of external human and material resources into China through both bilateral and multilateral channels for post-disaster reconstruction is advocated.

\section{Conclusions}

The importance, variety, complexity and multiplicity of resourcing problems post disaster require solutions to go beyond the mainstream procurement practice. Pre-event resource planning and preparedness is not just about assessment and preparation of the necessities for disaster recovery, but also requires pre-determined ways of working together with a range of stakeholders 
in the construction industry, construction market, governmental agencies to activate desirable resourcing strategies and procedures.

This study highlights four resourcing components for post-disaster reconstruction: legislation and policy, construction industry, construction market and transportation system. The study proposes a holistic view, showing where resourcing bottlenecks are likely to exist during post-disaster reconstruction and where efforts are needed to align resources more closely to reconstruction requirements after a disaster. Different resourcing efforts are proposed with an emphasis on enabling technical and institutional support from the government, industry and market and transport forces. The research also sets the basic steps for ameliorating resourcing operations and enhancing resourcing performance of the construction industry. However, the related operative measures and coordination initiatives among stakeholders to achieve a synthesis of the four identified areas are not addressed in the paper and could be critical issues for future research. This synthesis is likely to require reconstruction decision makers to improve legal and institutional arrangements to facilitate reconstruction work and reinforce policy execution capability.

Although based on China's reconstruction context, the research helps draw attention to four items which commonly face the reconstruction decision makers and practitioners and raises understanding of the key role of pre-event resource planning and preparedness to reduce the risks and vulnerabilities to future disasters. Through pre-event mapping, planning and preparedness in these areas, it is possible for disaster impacted or prone areas to be more resilient and prepared to deal with resourcing difficulties when a disaster strikes. 
Appendix: Table 3 SPSS one sample t-test result

\begin{tabular}{|c|c|c|c|c|c|}
\hline No. & $\begin{array}{l}\text { Factors affecting project resource availability } \\
\text { in post-disaster reconstruction }\end{array}$ & Mean & $t$-value & SD & $\begin{array}{l}\text { Significance } \\
\text { (2-tailed) }\end{array}$ \\
\hline & (I) Market-related factors & & & & \\
\hline 1. & Resource price fluctuation in market & 3.97 & 6.009 & 0.865 & 0.000 \\
\hline 2. & Local production capacity & 4.24 & 9.040 & 0.739 & 0.000 \\
\hline 3. & $\begin{array}{l}\text { Competition for resources from other reconstruction } \\
\text { projects }\end{array}$ & 4.07 & 8.844 & 0.651 & 0.000 \\
\hline 4. & $\begin{array}{l}\text { Competition for resources from other existing } \\
\text { construction projects }\end{array}$ & 3.59 & 3.829 & 0.825 & 0.001 \\
\hline \multirow[t]{2}{*}{5.} & Competition for resources from other industries & 3.34 & 1.625 & 1.143 & 0.115 \\
\hline & (II) Logistics-related factors & & & & \\
\hline 1. & Local transportation capacity & 4.38 & 9.581 & 0.775 & 0.000 \\
\hline 2. & Transportation method & 4.48 & 12.602 & 0.634 & 0.000 \\
\hline 3. & Transportation cost & 4.55 & 12.183 & 0.686 & 0.000 \\
\hline 4. & Resource procurement lead time & 4.59 & 12.520 & 0.682 & 0.000 \\
\hline \multirow[t]{2}{*}{5.} & Location of depot & 4.10 & 7.697 & 0.772 & 0.000 \\
\hline & (III) Project-related factors & & & & \\
\hline 1. & Project design drawings & 4.21 & 8.401 & 0.774 & 0.000 \\
\hline 2. & Quantity of resources required & 4.59 & 13.607 & 0.628 & 0.000 \\
\hline 3. & Project type & 4.00 & 5.203 & 1.035 & 0.000 \\
\hline 4. & Project schedule & 4.66 & 18.427 & 0.484 & 0.000 \\
\hline 5. & Project budget & 3.90 & 5.617 & 0.860 & 0.000 \\
\hline 6. & Type and method of construction & 3.66 & 4.118 & 0.857 & 0.000 \\
\hline 7. & Project procurement method & 4.00 & 6.075 & 0.886 & 0.000 \\
\hline 8. & Resource procurement contract type & 3.52 & 3.057 & 0.911 & 0.005 \\
\hline 9. & Project resourcing plan & 4.59 & 9.034 & 0.946 & 0.000 \\
\hline \multirow[t]{2}{*}{10.} & Location of construction site & 4.38 & 11.945 & 0.622 & 0.000 \\
\hline & (IV) Organization-related factors & & & & \\
\hline 1. & Qualification of contractor & 4.59 & 10.360 & 0.825 & 0.000 \\
\hline 2. & Selection of suppliers & 3.41 & 2.268 & 0.983 & 0.031 \\
\hline 3. & Partnership and supplier management & 4.14 & 8.250 & 0.743 & 0.000 \\
\hline 4. & Contractor resource database system & 4.48 & 13.899 & 0.574 & 0.000 \\
\hline 5. & Supplier inventory & 3.97 & 7.112 & 0.731 & 0.000 \\
\hline 6. & Contractor inventory & 4.14 & 7.353 & 0.833 & 0.000 \\
\hline 7. & Cooperation of parties in construction & 3.86 & 5.073 & 0.915 & 0.000 \\
\hline 8. & Coordination among parties in construction & 3.69 & 4.170 & 0.891 & 0.000 \\
\hline 9. & Communication with local authorities & 4.34 & 6.717 & 1.078 & 0.000 \\
\hline 10. & Contractor top management commitment & 3.62 & 3.186 & 1.049 & 0.004 \\
\hline \multirow[t]{2}{*}{11.} & Competency of resourcing manager & 4.59 & 9.855 & 0.867 & 0.000 \\
\hline & (V) Environment-related factors & & & & \\
\hline 1. & Legislation and policy & 4.83 & 25.601 & 0.384 & 0.000 \\
\hline 2. & General economic environment & 4.55 & 13.229 & 0.632 & 0.000 \\
\hline 3. & Local pre-event economic condition & 4.10 & 7.697 & 0.772 & 0.000 \\
\hline 4. & Physical impact of the disaster & 4.14 & 8.250 & 0.743 & 0.000 \\
\hline 5. & Social public attitude & 3.21 & 1.099 & 1.013 & 0.281 \\
\hline 6. & Community influence & 2.62 & -2.262 & 0.903 & 0.032 \\
\hline
\end{tabular}

Note: Scale ranges from $1=$ 'not important at all' to $5=$ 'very important'. The null hypothesis is $H_{0}: \mu=\mu_{0}$ and the alternative hypothesis is $H_{1}: \mu>\mu_{0}$, where $\mu$ is the population mean, $\mu_{0}$ is the critical rating at 3 . The level of significance for the one-tailed test is 0.05 .

\section{(c) Emerald Group Publishing Limited}

This is a pre-print of a paper and is subject to change before publication. This pre-print is made available with the understanding that it will not be reproduced or stored in a retrieval system without the permission of Emerald Group Publishing Limited. 


\section{References}

Alexander, D. (2004). "Planning for post-disaster reconstruction", I-Rec 2004 International Conference 'Improving Post-Disaster Reconstruction in Developing Countries', Coventry, UK.

Asian Development Bank (2007) Proposed loan for the reconstruction of the cement production facility in Aceh, Asian Development Bank.

Athukorala, P. C., and B. P. Resosudarmo (2005) "The Indian Ocean tsunami: Economic impact, disaster management and lessons". Asian Economic Papers 4(1): 1-39.

Berke, P. R., and T. J. Campanella (2006) "Planning for post-disaster resiliency". The ANNALS of the American Academy of Political and Social Science 604(1): 192-207.

Berke, P. R., J. Kartez, and D. Wenger (1993) "Recovery after disaster: Achieving sustainable development, mitigation and equity". Disasters 12(2): 94-109.

Birkland, T. A. (2006) Lessons of Disaster: Policy Change after Catastrophic Events, Georgetown University Press, Washington, D. C.

Bosher, L., P. Carrillo, A. Dainty, J. Glass, and A. Price (2007) "Realising a resilient and sustainable built environment: towards a strategic agenda for the United Kingdom". Disasters 31(3): 236-255.

Brunsdon, D., and S. Smith (2004). "Summary notes from the infrastructure workshop", New Zealand Recovery Symposium, Wellington, the Ministry of Civil Defence and Emergency Management.

Burby, R. J. (2006) "Hurricane Katrina and the paradoxes of government disaster policy: bringing about wise government decisions for hazardous areas". The ANNALS of the American Academy of Political and Social Science 604(1): 171-191.

Chang, H. J., R. Hargrove, Y. X. Long, and D. J. Osborne (2006) "Reconstruction after the 2004 tsunami: Ecological and cultural considerations from case studies". Landscape and Ecological Engineering 2(1): 41-51.

Clinton, W. J. (2006) Lessons Learned from Tsunami Recovery: Key Propositions for Building Back Better. Lessons Learned from Tsunami Recovery, Office of the UN Secretary-General's Special Envoy for Tsunami Recovery.

Davidson, C., G. Lizarralde, and C. Johnson (2008). "Myths and realities of prefabrication for postdisaster reconstruction", 4th International I-Rec Conference 2008 Building Resilience: achieving effective post-disaster reconstruction, Christchurch, New Zealand.

\section{(c) Emerald Group Publishing Limited}

This is a pre-print of a paper and is subject to change before publication. This pre-print is made available with the understanding that it will not be reproduced or stored in a retrieval system without the permission of Emerald Group Publishing Limited. 
Earthquake Reconstruction and Rehabilitation Authority (2006) 'Build Back Better' Reconstruction and Rehabilitation Strategy. Transport Sector, Government of Pakistan.

Edum-Fotwe, F. T., and R. McCaffer (2000) "Developing project management competency: Perspectives from the construction industry". International Journal of Project Management 18(2): 111-124.

Freeman, P. K. (2004) "Allocation of post-disaster reconstruction financing to housing". Building Research and Information 32(5): 427-437.

Gharaati, M. (2006). "An overview of the reconstruction program after the earthquake of Bam, Iran", IRec 2006 International Conference on Post-Disaster Reconstruction:' Meeting Stakeholder Interests', Florence, Italy.

Godschalk, D. R. (1999) Natural Hazard Mitigation: Recasting Disaster Policy and Planning, Island Press, Washington, D. C.

Hanaoka, S., and F. M. Qadir (2005). "Logistics problems in recovery assistance of Indian Ocean earthquake and tsunami disaster", Scientific Forum on The Tsunami, Its Impact and Recovery, Thailand, Asian Institute of Technology (AIT).

International Federation of Red Cross and Red Crescent Societies (2004) World Disaster Report 2004: Focus on Community Resilience. Geneva, IFRC.

International Federation of Red Cross and Red Crescent Societies (2006) Annual Report 2006, International Federation of Red Cross and Red Crescent Societies (IFRC).

Jayasuriya, S., and P. McCawley (2008) Reconstruction after A Major Disaster: Lessons from The PostTsunami Experience in Indonesia, Sri Lanka, and Thailand. ADBI Working Paper 125. Tokyo, ADB Institute.

Krippendorff, K. (1980) Content Analysis: An Introduction to Its Methodology, Sage Publications, Beverly Hills.

Lakshmi, A., and M. Bau (2007). "Project management needs in disaster situations: Lessons learnt from the Boxing Day Tsunami", 2007 PMI Global Congress Hongkong.

Limoncu, S., and B. Celebioglu (2006). "Post-disaster sustainable housing system in Turkey", I-Rec 2006 International Conference on Post-Disaster Reconstruction: 'Meeting Stakeholder Interests', Florence, Italy.

Litman, T. (2006) "Lessons from Katrina and Rita: what major disasters can teach transportation planners". Journal of Transportation Engineering 132(1): 86-95.

(c) Emerald Group Publishing Limited

This is a pre-print of a paper and is subject to change before publication. This pre-print is made available with the understanding that it will not be reproduced or stored in a retrieval system without the permission of Emerald Group Publishing Limited. 
Lyons, M. (2009) "Building back better: the large-scale impact of small-scale approached to reconstruction". World Development 37(2): 385-398.

Manyena, S. B. (2006) "The concept of resilience revised". Disasters 30(4): 433-450.

Masurier, J. L., J. Rotimi, and S. Wilkinson (2006). "A comparison between routine construction and post-disaster reconstruction with case studies from New Zealand", 22nd ARCOM Conference on Current Advances in Construction Management Research, Birmingham, U. K.

Masurier, J. L., S. Wilkinson, and Y. Shestakova (2006). "An analysis of the alliancing procurement method for reconstruction following an earthquake", In Proceedings of the 8th US National Conference on Earthquake Engineering, San Francisco, California.

Masurier, J. L., S. Wilkinson, K. Zuo, and J. Rotimi (2008). "Building resilience by focusing on legal and contractual frameworks for disaster reconstruction", International Workshop on Post-Earthquake Reconstruction and Safe Buildings, Chengdu, Sichuan, China, Sichuan University \& Sichuan Postdisaster Reconstruction Support and Research Centre.

McEntire, D. A., C. Fuller, C. W. Johnston, and R. Weber (2002) "A comparison of disaster paradigms: the search for a holistic policy guide". Public Administration Review 62(3): 267-280.

McGee, R. W. (2008) "An economic and ethical analysis of the Katrina disaster". International Journal of Social Economics 35(7): 546-557.

McManus, S., E. Seville, D. Brunsdon, and J. Vargo (2007) Resilience Management: A Framework for Assessing and Improving the Resilience of Organisations. Resilient Organisations Research Report, Resilient Organisation Research Program.

Mitchell, J. K. (2004). "Reconceiving Recovery", Recovery Symposium 2004, Napier, The Ministry of Civil Defence and Emergency Management.

National People's Congress of the People's Republic of China (1998) Law of the People's Republic of China on Protecting against and Mitigating Earthquake Disasters. National People's Congress of the People's Republic of China.

National People's Congress of the People's Republic of China (2007) Emergency Response Law of the People's Republic of China. National People's Congress of the People's Republic of China.

Nazara, S., and B. P. Resosudarmo (2007) Aceh-Nias Reconstruction and Rehabilitation: Progress and Challenges at the End of 2006. Tokyo, Asian Development Bank Institute.

\section{(c) Emerald Group Publishing Limited}

This is a pre-print of a paper and is subject to change before publication. This pre-print is made available with the understanding that it will not be reproduced or stored in a retrieval system without the permission of Emerald Group Publishing Limited. 
Orabi, W., K. EI-Rayes, A. B. Senouci, and H. AL-Derham (2009) "Optimizing post-disaster recontruction planning for damaged transportation networks". Journal of Construction Engineering and Management in press: unknown.

Paton, D., and D. Johnston (2001) "Disasters and communities: vulnerabilities, resilience and preparedness". Disaster Prevention and Management 10(4): 270-277.

Perry, R. W., and M. K. Lindell (2003) "Preparedness for emergency response: Guidelines for the rmergency planning process". Disasters 27(4): 336-350.

Pheng, L. S., and Q. T. Chuan (2006) "Environmental factors and work performance of project managers in the construction industry". International Journal of Project Management 24(1): 24-37.

Pheng, L. S., B. Raphael, and W. K. Kit (2006) "Tsunamis: some pre-emptive disaster planning and management issues for consideration by the construction industry". Structural Survey 24(5): 378396.

Pribadi, K., D. Hoedajanto, and T. Boen (2003). "Earthquake disaster mitigation activities in Indonesia Jan 1999 - Nov 2003", the 3rd WSSI International Workshop, Bangkok, Thailand, The University of Tokyo, Japan.

Resilient Organisations (2006) Barriers to Post-Disaster Reconstruction. Resilient Organisations Research Report. Wellington, Resilient Organisations.

Roseberry, R. (2008). "A balancing act: An assessment of the environmental sustainability of permanent housing constructed by international community in post-disaster Aceh", 4th International I-Rec Conference 2008 Building Resilience: achieving effective post-disaster reconstruction, Christchurch, New Zealand.

Rowland, J. (1995) "Rebuilding Sarajevo". Disaster Prevention and Management 4(1): 32-37.

Schilderman, T. (2004) "Adapting traditional shelter for disaster mitigation and reconstruction: Experiences with community-based approaches". Building Research and Information 32(5): 414426.

Sichuan Provincial People's Government (2008) Press Conference for Housing Building Materials in Earthquake-stricken Areas, Retrieved 15th December 2008.

Singh, B. (2007) Availability of Resources for State Highway Reconstruction : A Wellington Earthquake Scenario Civil and Environmental Engineering Department. Auckland, The University of Auckland. Master Thesis.

\section{(c) Emerald Group Publishing Limited}

This is a pre-print of a paper and is subject to change before publication. This pre-print is made available with the understanding that it will not be reproduced or stored in a retrieval system without the permission of Emerald Group Publishing Limited. 
Singh, B. (2007) Availability of Resources for State Highway Reconstruction : A Wellington Earthquake Scenario Civil and Environmental Engineering Department. Auckland, The University of Auckland. Master thesis.

Spence, R., and I. Kelman (2004) "Editorial: Managing the risks from natural hazards". Building Research and Information 32(5): 364-367.

State Planning Group of Post-Wenchuan Earthquake Restoration and Reconstruction (2008) The State Overall Planning for Post-Wenchuan Earthquake Restoration and Reconstruction. National Development and Reform Committee.

Steinberg, F. (2007) "Housing reconstruction and rehabilitation in Aceh and Nias, Indonesia — rebuilding lives". Habitat International 31(1): 150-166.

Sullivan, M. (2003) "Integrated Recovery Management: A New Way of Looking at A Delicate Process". The Australian Journal of Emergency Management 18(2): 5-27.

The State Council of the People's Republic of China (2008) One-on-one Assistance Program for PostWenchuan Earthquake Restoration and Reconstruction. The State Council of the People's Republic of China.

The State Council of the People's Republic of China (2008) Regulations on Post-Wenchuan Earthquake Restoration and Reconstruction. The State Council of the People's Republic of China.

Thompson, S., N. Altay, W. G. Green, and J. Lapetina (2006) "Improving disaster response efforts with decision support systems". International Journal of Emergency Management 3(4): 250-263.

Todd, D. J. (1979) "Mixing Qualitative and Quantitative Methods: Triangulation in Action". Administrative Science Quarterly 24: 602-611.

Troy, D. A., A. Carson, J. Vanderbeek, and A. Hutton (2008) "Enhancing community-based disaster preparedness with information technology". Disasters 32(1): 149-165.

United Nations Development Programme (2005) Survivors of The Tsunami: One Year Later, United Nations Development Programme (UNDP).

United Nations Thailand (2005) Build Back Better, Tsunami in Thailand.

Ye, Y., and N. Okada (2002). "Integrated relief and reconstruction management following a natural disaster", Second Annual IIASA-DPRI Meeting, Integrated Disaster Risk Management: Megacity Vulnerability and Resilience, Luxenburg, Australia. 
Zuo, K., R. Potangaroa, and S. Wilkinson (2008). "Supply chain analysis and the sustainability of postdisaster construction: The Boxing Day Tsunami reconstruction experience in Aceh, Indonesia", International Workshop on Post-Earthquake Reconstruction and Safe Buildings, Chengdu, Sichuan, China, Sichuan University \& Sichuan Post-disaster Reconstruction Support and Research Centre.

Zuo, K., and S. Wilkinson (2008) Supply chain and material procurement for post disaster construction: the Boxing Day Tsunami reconstruction experience in Aceh, Indonesia. CIB W89 International Conference on Building Education and Research BEAR 2008. Heritance Kandalama, Sri Lanka.

Zuo, K., S. Wilkinson, J. L. Masurier, and J. V. D. Zon (2006). "Reconstruction procurement systems: The 2005 Matata flood reconstruction experience", I-Rec 2006 International Conference on PostDisaster Reconstruction: 'Meeting Stakeholder Interests', Florence, Italy. 